\title{
A GESTÃO AMBIENTAL NOS CURSOS DE ADMINISTRAÇÃO: UMA ANÁLISE DA PERSPECTIVA DOS PROFESSORES
}

\author{
ENVIRONMENTAL MANAGEMENT IN ADMINISTRATION \\ COURSES: AN ANALYSIS OF THE FACULTY PERSPECTIVE
}

\author{
Leonel Gois Lima Oliveira ${ }^{1}$, Davi Montefusco de Oliveira ${ }^{2}$ \\ e Francisco José da Costa ${ }^{3}$
}

\begin{abstract}
Resumo
Este estudo buscou avaliar a importância atribuída por professores de Instituições de Ensino Superior em Administração para a área de Gestão Ambiental, além de analisar as intenções futuras desses profissionais em relação a essa mesma área. Foram levantados dados junto a 41 professores de diferentes instituições na cidade de Fortaleza. Os dados foram analisados por meio de Estatísticas Descritivas (médias, desvios padrão e frequências). Os resultados indicaram principalmente que: (1) os professores avaliam que a gestão ambiental é uma área de grande relevância para os cursos de Administração e, ainda, que há uma necessidade moderada desta área nos cursos; (2) por outro lado, e apesar da grande relevância atribuída, o nível de intenções de envolvimento dos professores com a área foi baixo. Os resultados trazem informações relevantes para professores, gestores de instituições e autores de materiais didáticos, que poderão direcionar mais consistentemente as atividades de formação.
\end{abstract}

Palavras-chave: Gestão Ambiental; Cursos de Administração; Professores; Ensino; Currículo.

\footnotetext{
${ }^{1}$ Mestrando em Administração pela Universidade Estadual do Ceará. E-mail: leonelgois@gmail.com

${ }^{2}$ Mestrando em Administração pela Universidade Estadual do Ceará. E-mail: davi_montefusco@yahoo.com.br

${ }^{3}$ Doutorado em Administração de Empresas pela FGV/EAESP, Professor da Universidade Estadual do Ceará. E-mail: franzecosta@gmail.com
} 


\begin{abstract}
This objective of this study was to evaluate the importance attributed by Management administration faculty to the area of Environmental management, and also to analyze the future intentions of these professionals regarding this area. Data from a total 41 professors of different institutions from the city of Fortaleza were collected by using a structured questionnaire. These data were analyzed by means of descriptive statistics (average, standard deviations, and frequencies). The results indicated mainly that: (1) the professors evaluate that the environmental management is an area of great relevance for the Administration courses, and that there is has a moderate necessity of this area in the courses; (2) on the other hand, and although the great relevance attributed to the area, the professors intentions of involvement with the area was of low level. The results bring consistent information for professors, managers of institutions, and authors of instructional materials, and can contribute for a better execution their educational activities.
\end{abstract}

Keywords: Environmental management; Administration courses; Faculty; Teaching; Curriculum.

\title{
1 Introdução
}

O debate sobre as questões ambientais vem ganhando crescente importância no contexto organizacional, público ou empresarial, em razão dos constantes alertas de cientistas e de organismos multilaterais sobre as consequências de um modelo de gestão sem responsabilidade ambiental, além da percepção dos gestores de que o aspecto é já importante para a decisão dos consumidores. Com efeito, a preocupação atual sobre o meio ambiente representa uma mudança de paradigma quanto às perspectivas futuras do meio empresarial e da sociedade em si.

Por outro lado, é possível observar que o campo da gestão ambiental ainda está em formação, contendo muitas ausência de práticas decisivas e lacunas teóricas para uma mudança plena das atividades gerenciais. A interpretação de Egri e Pinfild (1996), quanto à existência de várias questões teóricas que permanecem sem solução na literatura da teoria sociológica e organizacional sobre sistemas sociais, assim como na teoria ecológica sobre os sistemas ecológicos, apresentada há mais de 10 anos, permanece presente com grande intensidade nas discussões referentes a esta temática. No entanto, é intenso o movimento de pensadores e instituições de ensino no sentido de explorar e desenvolver o tema.

Conforme Esty e Winston (2006), este movimento, que chamou de a 'Onda Verde', abrange todas as modalidades de organizações empresariais, e aquelas que estiverem mais bem adaptadas obterão sucesso no futuro. Corroborando com este pensamento, Lash e Wellington (2007) destacam a importância de que as empresas estejam o mais rápido possível preparadas para o desafio de uma gestão ambientalmente responsável, pois estas, certamente conseguirão evidência e alcançarão uma melhor vantagem competitiva. Desta maneira, a adequação das empresas aos conceitos e práticas do gerenciamento ambiental tornar-se-ia um diferencial desejável perante seus stakeholders.

Neste contexto, acredita-se que cabe às instituições de ensino protagonizar a elaboração e execução de projetos de gestão e de educação ambiental, como um elemento viável para uma formação profissional consistente e alinhada com as principais demandas da atualidade e do futuro. Tal propósito requer uma maior atenção na identificação dessas demandas, principalmente em nível local. Ademais, além da formação da consciência, requer-se também a formação de competências para atuação em um contexto multidisciplinar e complexo (RIGONAT, 2002).

Nessa realidade é que desenvolvem as discussões em torno da preocupação gerencial, no que, convencionalmente, se chama de gestão ambiental. Uma análise exploratória do que

Rev. Adm. UFSM, Santa Maria, v. 3, n. 2, p. 205-218, mai./ago. 2010 
se tem estudado acerca dessa temática aponta os mais diversos posicionamentos colocados por gestores, professores ou pensadores e é desafio deste trabalho contribuir neste debate.

Assim, definiu-se como propósito avaliar o tema pela perspectiva dos professores, considerando a importância atribuída ao tema ambiental para a formação em Administração. De modo específico, buscou-se avaliar a importância atribuída por profissionais da educação superior em Administração para a área de gestão ambiental, além de analisar as intenções futuras desses professores em relação a essa mesma área.

O trabalho deve, portanto, oferecer informações para que gestores de cursos e de instituições que oferecem cursos na área de Administração direcionem mais consistentemente os projetos de formação de gestores para um campo que tende a apresentar, já presentemente, uma grande demanda de administradores profissionais. Este direcionamento perpassa pelo conteúdo ministrado pelos professores em suas disciplinas, principalmente naquelas que possuem uma relação direta com a formação em gestão ambiental.

O restante do trabalho está estruturado em quatro seções. A próxima parte irá descrever os fundamentos teóricos do tema. No item seguinte, é explicitado o caminho metodológico seguido para o alcance dos resultados. Posteriormente, expõem-se os resultados e as análises da pesquisa de campo realizada, enquanto que no último item são feitas as considerações e recomendações finais.

\section{Revisão teórica}

Neste item, apresentam-se os embasamentos teóricos do estudo. Considerou-se apropriado dividir o item em duas etapas: inicialmente, comentam-se os fundamentos da gestão ambiental e da formação na área; e, em seguida, são apresentados e comentados alguns trabaIhos que foram considerados relevantes para a elaboração do artigo.

\subsection{Gestão ambiental e seus principais fundamentos}

A gestão ambiental ainda é um campo em formação e, por esta razão, alguns conceitos, ações e práticas estão em busca de uma melhor consolidação teórica e pragmática. Conforme consta em Silva, Silva e Enders (2006), um conceito consistente de gestão ambiental é aquele que a entende como sendo uma estrutura gerencial que permite que a organização visualize os impactos de suas ações no meio ambiente. Para tanto, a organização deve desenvolver um sistema que permita e facilite o acesso, a catalogação e a quantificação dos impactos ambientais das operações de toda organização.

Em uma avaliação do entendimento de Silva, Silva e Enders (2006), fica evidente uma vinculação do conceito de gestão ambiental ao contexto organizacional, ou seja, a proposta relaciona-se mais ao impacto das ações organizacionais (principalmente empresariais), do que na composição de esforços para atingir estes mesmos objetivos. A gestão ambiental seria, portanto, mais um grupo de ações para minimizar o impacto das ações potencialmente hostis ao meio ambiente, do que um conjunto de ações para colaborar com a aquisição dos objetivos em si. Enquanto para Melo Neto e Brennad (2004), a gestão ambiental representa o último estágio de atuação da empresa em relação à problemática do meio ambiente.

Deve-se verificar que a gestão ambiental em nível organizacional apresenta diferenças do conceito em nível governamental, posto que os governos praticam ações com a intenção restrita ao meio ambiente em si, enquanto a maioria das demais organizações têm outras fina- 
lidades em termos de produção, ou seja, não são diretamente ligadas ao propósito ambiental. O emprego da mesma expressão para os dois contextos (organizacional e governamental) permite a possibilidade de confusão conceitual.

Verificando a necessidade de uma melhor demarcação da área, Barbieri (2004) observou que qualquer proposta de gestão ambiental inclui, no mínimo, três dimensões, a saber: (1) a dimensão espacial, que concerne à área na qual se espera que as ações de gestão ambiental tenham eficácia; (2) a dimensão temática, que delimita sobre quais questões ambientais as ações se destinam; e (3) a dimensão institucional, relativa aos agentes que tomam iniciativas de gestão. A proposta de Barbieri (2004) ilustra uma tentativa de delimitação que envolve tanto o nível organizacional quanto o governamental, ainda que a proposta atenda melhor ao segundo contexto.

Acredita-se que as ações dos governos ganham maior consistência e os resultados passam a ser melhores a partir do envolvimento da sociedade civil e do universo empresarial. Daí provém a relevância da formação em gestão ambiental para estudantes de cursos de Administração, seja com orientação para empresas seja para quaisquer outros tipos de organização.

É possível observar, no universo empresarial, a tentativa de se buscar responder aos anseios sociais, estabelecendo regras particulares como forma de guiar as organizações em suas ações ambientais. Em nível internacional, destaca-se o posicionamento da Associação Espanhola de Contabilidade e Administração de Empresas, que estabeleceu regras para o comportamento e atuação das empresas em suas funções econômicas. No Brasil, destaca-se o posicionamento do Instituto Ethos, que propõe diretrizes e dá o devido reconhecimento para empresas que mantêm compromisso com o meio ambiente (INSTITUTO ETHOS, 2005a; 2005b).

Destaca-se, ainda, a existência de uma norma internacional quanto ao gerenciamento ambiental, a norma ISO 14001, que foi elaborada pela International Organization for Standardization (ISO), fundada no ano de 1947, localizada em Genebra, na Suíça. Ressalta-se que, nesse caso, esta é uma norma de gerenciamento, não se apresentando como uma norma de desempenho ou de produto. Seu propósito é focalizar o processo de gerenciamento das atividades da organização que possuem impacto no ambiente (NASCIMENTO; LEMOS; MELLO, 2008). Ademais, tem-se que os requisitos da norma são baseados nos seguintes aspectos: exigências gerais; política ambiental; planejamento; execução e operação; verificação e ação corretiva; e revisão da administração (ABNT, 2004).

Especificamente em nível de formação, verificou-se, na literatura, a existência de alguns trabalhos que abordam a temática relacionada à gestão ambiental, buscando a educação ambiental a partir do trabalho com crianças até o nível universitário ou mesmo profissional. (REIGOTA, 1994; CAPRA, 2007; NASCIMENTO; LEMOS; MELLO, 2008).

No Brasil, a abordagem da temática ambiental para formação foi, inclusive, regulamentada pela Lei no. 9.795, de 27 de abril de 1999 (Política Nacional de Educação Ambiental no Brasil), que definiu a obrigatoriedade de se abordar o tema ambiental de forma transversal nos currículos escolares. Especificamente sobre a gestão ambiental, a Lei prevê que a política de educação ambiental deverá promover "a preparação de profissionais orientados para as atividades de gestão ambiental" (BRASIL, 2007).

Uma questão que se depreende bastante neste caso, diz respeito sobre como e em quais os locais seria realizada a preparação destes profissionais. Em uma primeira análise, é razoável imaginar que as escolas de Administração seriam os locais adequados (mas não exclusivos) para formação desses profissionais, pois o trabalho de gestão é intrínseco à profissão. Além disso, tal formação também poderia concretizar-se na forma de cursos unicamente direcionados, seja na forma de habilitações, seja mesmo na oferta de disciplinas. 
Mesmo depois de quase uma década da Lei 9.795, o campo ainda não ganhou total consolidação e o próprio ambiente acadêmico também reflete o quanto a área ainda é emergente. A gestão ambiental, que foi inicialmente estudada nos cursos de pós-graduação, passou a ser analisada em cursos de graduação, através de diversos meios, como, por exemplo: em tópicos de livros didáticos (cf. MAXIMIANO, 2004), especialmente em capítulos sobre responsabilidade social; em Atividades Complementares e Projetos Especiais, conforme verificado em diversas instituições; em disciplinas dos cursos, conforme visto, por exemplo, no curso de graduação em Administração, na Universidade de Fortaleza (UNIFOR); e ainda em cursos superiores de graduação, como no caso da Escola Superior de Agricultura Luiz de Queiroz (ESALQ USP) e também na Universidade Federal do Paraná, além de vários cursos na modalidade tecnológica.

A proposta de um maior desenvolvimento da área, como procedido pela ESALQ há pelo menos cinco anos, é merecedora de alguns comentários adicionais (ESALQ, 2007): primeiramente, verifica-se que a temática ganhou um direcionamento maior para a área de Ciências Agrárias, ainda que se admita que a formação de base do curso seja fortemente embasada em Administração; ademais, também é interessante a avaliação feita dos campos de atuação do bacharel em gestão ambiental, que poderá atuar junto a empresas do setor privado, organizações não-governamentais (ONG's), entidades públicas, instituições relacionadas com questões ambientais em decorrência de sua própria atividade (como as áreas de mineração, química, siderúrgica etc.), entre outros lugares, e que busquem profissionais realmente formados e com visão de negócio.

O papel definido para os gestores para esta escola (ESALQ) seria, em nível de empresas, "assumir a implementação e coordenação de sistemas de gestão ambiental", além de "emitir pareceres, relatórios, planos, projetos, arbitragens e laudos, em que se exija a aplicação de conhecimentos inerentes à área das ciências ambientais e às técnicas de organização"; além de "conduzir pesquisa, estudo, análise, interpretação, planejamento, implantação, coordenação e controle de trabalhos nos campos das ciências ambientais e da administração geral".

A proposta da ESALQ parece consistente com a demanda de uma formação mais extensiva, para além dos tópicos sobre o tema, outrora dispersos nas várias disciplinas dos cursos de Administração. Fato esse que é comprovado na pesquisa sobre Perfil, Formação, Atuação e Oportunidades de Trabalho do Administrador (ANDRADE et al., 2006), na qual, dentre os novos conteúdos que foram sugeridos às Instituições de Ensino Superior para integrarem suas disciplinas e melhor formarem seus alunos dentro da realidade de mercado, estava incluída a temática da gestão ambiental, que foi apontada como a segunda de maior necessidade nos cursos de graduação.

Por outro lado, é ainda imperativo que os cursos de Administração, na sua modalidade clássica, preocupem-se com o tema, e mesmo se esforcem para promover a formação de profissionais para atender às diversas demandas existentes. A questão que surge, aqui nesse caso, é se os professores também percebem esta necessidade e o quanto eles se propõem para contribuir para o desenvolvimento e crescimento da mesma. Sendo assim, avaliar esta questão é a finalidade central deste trabalho.

\subsection{Pesquisas relevantes para o estudo}

Se em relação à formação, tem-se ainda uma evidente demanda por consolidação, no que se refere à dimensão da pesquisa, pode-se atestar, por outro lado, um extensivo desenvolvimento nos últimos 15 anos. No Brasil, a área tem seu próprio evento acadêmico (o Encontro 
Nacional sobre Gestão Empresarial e Meio Ambiente - ENGEMA), e é área de concentração nos principais eventos nacionais (como no Encontro Nacional da Associação Nacional de PósGraduação e Pesquisa em Administração - EnANPAD), além de ter um bom elenco de pesquisadores concentrados na área, tanto no Brasil quanto no exterior.

$\mathrm{Na}$ análise dos estudos, foi dada maior atenção aos casos que avaliavam a formação em gestão ambiental, embora se perceba que o tema é abordado de forma apenas transversal por diversos autores (BARBIERI, 2004; DIAS, 2006; SEIFFERT, 2007; TACHIZAWA, 2007). Dentre os trabalhos pesquisados em nível nacional, considerou-se relevantes as pesquisas de Santos et al. (2000) e Gonçalves-Dias et al. (2006).

O estudo desenvolvido por Santos et al. (2000) partiu da compreensão de que as instituições de formação de gestores exercem um papel relevante na solução da questão ambiental. Assim, foi analisada a experiência de um projeto de gestão ambiental desenvolvido por um conjunto de estudantes. $\mathrm{Na}$ análise da experiência, os autores encontraram dificuldades de alinhamento de visão entre estudantes e os empresários, em razão da centralidade dos objetivos empresariais na mentalidade dos empreendedores. O estudo teve a limitação de ser baseado em apenas um caso, mas parece ilustrar bem a necessidade de desenvolvimento de outra mentalidade em relação ao papel empresarial nesse tipo de situação.

Já o estudo de Gonçalves-Dias et al. (2006) foi mais focado na necessidade de inserir a temática da gestão ambiental no universo dos cursos de graduação em Administração. Assim, com os objetivos de caracterizar a dimensão ecológica do comportamento de futuros administradores e de apontar condições, desafios e perspectivas para a ampliação da formação sócioambiental, os autores pesquisaram uma amostra de 341 graduandos em Administração de uma Instituição de Ensino Superior localizada em São Paulo. Os resultados encontrados indicaram que a formação e o avanço da consciência ambiental caminham por trilhas tortuosas, o que exige do ensino em Administração novos esforços no sentido de compreender as questões ambientais na formação de futuros administradores. Todavia, este estudo teve a limitação de ser focado em uma só instituição.

Em nível internacional, destaca-se o trabalho de Shafer (2006) que analisou, junto a 302 estudantes de cursos de Master in Business Administration (MBA) americanos, o relacionamento entre o que chamou de 'paradigma social e paradigma ecológico', além de verificar a avaliação que os estudantes fazem sobre a questão da responsabilidade ambiental. Os resultados do autor apontaram que a atitude positiva dos estudantes em relação ao paradigma ambiental implica na disposição em promover ações ligadas à questão da responsabilidade ambiental.

Um estudo semelhante foi desenvolvido pelo mesmo autor, em coautoria (FUKUKAWA; SHAFER; LEE, 2007), desta vez com o objetivo de analisar o relacionamento entre os valores pessoais de estudantes de cursos de MBA (100 respondentes no total) e o apoio a ações de responsabilidade ambiental. Os resultados deste estudo foram submetidos a uma análise fatorial, tendo-se identificado que os estudantes mostraram disposição em apoiar ações de responsabilidade ambiental nas empresas; além da concordância de que os governos devem impor condições para o gerenciamento ambientalmente responsável dentro das empresas. Os dois estudos, a despeito de parecerem abordar o óbvio, têm o mérito de fundamentar suas conclusões em dados empíricos.

Para este artigo, o propósito é seguir em convergência com algumas das preocupações inerentes a estes estudos supracitados, porém transferindo a perspectiva para a visão dos professores, os quais também poderão e deverão ter papel fundamental no encaminhamento de ações de gestão ambiental nos seus respectivos cursos. Tal proposta de se entender o nível de importância da gestão ambiental foi complementada com a avaliação das expectativas futuras 
de envolvimento com a área. Nesta perspectiva, foi desenvolvido um estudo empírico, cujos detalhes estão descritos no item seguinte.

\section{Metodologia}

O trabalho foi desenvolvido em três etapas: procedimentos exploratórios, definição do instrumento e coleta de dados, e trabalho empírico. Os procedimentos exploratórios foram desenvolvidos em duas fases. A primeira constou da pesquisa bibliográfica, exposta no item anterior, e a segunda fase consistiu nos procedimentos exploratórios gerais.

Nesse caso, procurou-se identificar, primeiramente, estudos empíricos com ideias semelhantes e/ou relacionadas aos objetivos deste estudo, especialmente para identificar possíveis escalas para mensuração e definição dos construtos.

A partir desses procedimentos iniciais, foi selecionado o questionário, como instrumento de coleta de dados. Foi decidido que tal instrumento seria dividido em três blocos: o primeiro deles contendo as variáveis de identificação relacionadas à formação e à experiência do professor; o segundo bloco envolvendo as questões dos construtos do estudo; e, por fim, o terceiro bloco trazia questões sobre dados demográficos e socioeconômicos.

Para a definição dos itens dos construtos e visando à análise da relevância da gestão ambiental, foi especialmente importante o estudo de Sleeper et al. (2006), no qual foi desenvolvida uma escala para avaliação do 'papel da educação em negócios em relação aos temas sociais' (Escala BERSI - [B]usiness [E]ducation's [R]ole in addressing [S]ocial [I]ssues), desenvolvida junto a estudantes universitários. Os 10 itens desta escala foram traduzidos, analisados e adaptados para o contexto da gestão ambiental (substituindo os temas sociais) e, em seguida, ajustados para a perspectiva dos professores.

A análise de sentido dos itens da escala deixou evidentes duas dimensões centrais na pesquisa, uma sobre a relevância da área para a formação em Administração e a segunda sobre a percepção de necessidade da área nos curso. Além dos itens da escala que originaram essas duas dimensões, também foram definidos, a partir dos tópicos da literatura pesquisada, quatro itens para avaliar a predisposição dos professores em manter envolvimento futuro com a gestão ambiental.

Os dez itens sobre a percepção da relevância da gestão ambiental foram apresentados como afirmações, com averiguação do grau de concordância por meio de uma escala de Likert de 5 pontos, com extremos de 1 para 'discordância total', e 5 para a 'concordância total'. Já nos quatro itens sobre intenções futuras, questionava-se a probabilidade de o respondente seguir a alternativa de envolvimento proposta, em uma escala de 5 pontos, com extremos de 1 para 'muito improvável', e 5 para 'muito provável. Após a consolidação preliminar do instrumento, este foi submetido a um pré-teste e, após os devidos ajustes, o questionário foi aplicado. Nesta etapa, foram delineadas as seguintes configurações:

- universo da pesquisa: o universo da pesquisa foi constituído por professores de cursos de graduação em Administração das Instituições de Ensino Superior do Ceará;

- amostra: a amostra total foi formada por 41 professores, selecionados junto a instituições cearenses;

- método de coleta: a coleta de dados foi procedida pelos autores. A abordagem foi realizada diretamente nos próprios locais de trabalho de cada um deles;

- tempo: os questionários da amostra foram aplicados entre os meses de junho e julho de 2008. O tempo aproximado de resposta foi de 10 minutos. 
Para a análise dos resultados dos dados coletados, procedeu-se, inicialmente, a uma avaliação preliminar, com a verificação de valores faltantes (missing values), assim como sobre a existência de valores atípicos (ouliers), especialmente nos itens dos construtos. Em seguida, foi feita a apresentação descritiva dos resultados das variáveis categóricas.

Adicionalmente, foram selecionadas as médias e os desvios padrão de cada uma das variáveis independentemente e, em seguida, da medida geral do construto, com composição pela média das entradas das variáveis componentes (levando-se em contato os cuidados recomendados por BAGOZZI; EDWARDS, 1998).

Todos os procedimentos estatísticos foram desenvolvidos com suporte nas recomendações de autores especialistas nas técnicas utilizadas (HAIR et al. 2005; MALHOTRA, 1999), e foram realizados por meio do software SPSS, versão 13.

\section{Análise de dados}

Para a avaliação dos dados da pesquisa de campo, decidiu-se pela exposição em quatro momentos distintos: inicialmente apresentam-se os resultados da análise preliminar dos dados; em seguida, apresenta-se a descrição da amostra; a terceira parte apresenta os procedimentos da análise dos construtos da pesquisa; e, por fim, são apresentados alguns comentários adicionais sobre os resultados encontrados.

\subsection{Análise preliminar}

Com a finalidade de avaliar os dados, optou-se, inicialmente, pela avaliação dos valores faltantes e dos valores atípicos das variáveis dos construtos centrais da pesquisa. A avaliação foi feita sobre as 41 entradas de dados tabuladas. Especificamente nas variáveis dos construtos da pesquisa, não foram encontrados valores faltantes. Assim, não foi necessário qualquer procedimento de ajuste para esta primeira avaliação.

Não foi verificada também a normalidade das variáveis dos construtos por meio das medidas de assimetria e de curtose das variáveis dos construtos (provavelmente pelo pequeno tamanho da amostra). Considerando os objetivos deste estudo, a falta de normalidade não provoca problemas nas análises subsequentes, apesar de ser conveniente que as variáveis sejam normais (HAIR et al. 2005). De posse dessas informações, seguiu-se para os procedimentos posteriores, conforme descrito nos itens que seguem.

\subsection{Descrição da amostra}

Das 41 entradas consideradas, a maioria $(31,7 \%)$ corresponde a professores com a formação de graduação em Administração. As outras formações foram as seguintes: Economia $(24,4 \%)$; Contabilidade e Psicologia (7,3\%, cada uma); Direito, Engenharia Civil e Letras (4,9\%, cada uma); e, por fim, Engenharia Agronômica, Engenharia Química, História, Informática, Matemática e Sociologia (2,4\%, cada uma).

Quanto à maior titulação consolidada, 25 (61\%) indicaram serem mestres, 4 (9,8\%) eram especialistas, $12(29,3 \%)$ respondentes possuíam doutorado. Tais dados parecem refletir bem a realidade do universo de professores de cursos de Administração, conforme atestado na pesquisa sobre o perfil dos professores da graduação em Administração (ANDRADE et al., 2006). 
Quanto à sua disciplina ter relação direta com a gestão ambiental, a divisão foi bem equilibrada, com 20 (48,8\%) dos respondentes afirmando que 'sim' e $21(51,2 \%)$ respondendo que 'não'. Desdobraram-se os motivos sobre por que suas disciplinas possuíam a relação. Assim, 9 (45\%) deles explicaram que a gestão ambiental é um tópico que entra como tema transversal da disciplina; 4 (20\%) disseram que sua disciplina era de tema aberto e inseria a gestão ambiental por conta própria, e somente $2(10 \%)$ deles disseram que a gestão ambiental é uma das unidades centrais da disciplina ministrada (5 respondentes [25\%] assinalaram a opção 'outros').

Quando indagados sobre como, academicamente, a temática da gestão ambiental deveria ser abordada, a maioria dos respondentes $(46,3 \%)$ disse que deveria ser uma disciplina dos currículos de graduação em Administração, enquanto 39,0\% entenderam que o assunto deveria ser analisado com conteúdo interdisciplinar de um curso de Administração; e; por fim; um total de 7,3\% afirmou que o tema deveria ser abordado como 'Atividades Complementares'. Estes últimos percentuais são indicativos de que uma disciplina no curso e/ou projetos acadêmicos satisfariam o interesse da grande maioria dos professores. Ademais, foi pequeno o percentual de alunos que entenderam que a gestão ambiental deveria ser trabalhada em um curso específico $(4,9 \%)$, complementarmente ao fato de que apenas $2,4 \%$ indicaram 'outros' como alternativa.

Quanto ao sexo dos respondentes, 68,3\% foram de homens e 31,7\% de mulheres. Já no que diz respeito à distribuição por idade, 2,4\% apontaram ter 'até 30 anos', 51,2\% apontaram ter 'acima de 30 até 40 anos', 36,6\% apontaram idade 'acima de 40 até 50 anos', 4,9\% apontaram idade 'acima de 50 até 60 anos', enquanto 4,9\% indicaram ter 'acima de 60 anos'. Sobre o estado civil dos pesquisados, $14,6 \%$ informaram serem solteiros, $70,7 \%$ apontaram serem casados e $14,6 \%$ indicaram a opção 'outros'.

\subsection{Análise dos construtos da pesquisa}

No que diz respeito à análise do fator 'relevância da área para o curso', as médias dos itens da escala foram acima de 4 em quatro das cinco variáveis, como demonstra a tabela 1. Tendo-se em vista que as escalas foram de 1 a 5, é possível entender que os professores atribuem uma grande relevância para a área, considerando-se essas quatro variáveis. Já a variável que restou ficou com uma média em torno de $4(3,80)$, que, apesar de ser um valor abaixo das demais, ainda assim indica um nível de concordância relativamente elevado com a afirmação feita. Com relação aos desvios padrão das variáveis dos construtos, quatro das cinco variáveis tiveram valores abaixo de 1,00, o que pode ser considerado baixo, indicando-se, assim, uma boa convergência de opiniões.

Um dos pontos interessantes sobre os dados apresentados na tabela 1 é a indicação de que os professores, além da grande importância atribuída ao aprendizado sobre gestão ambiental na formação em Administração, também acreditam que as escolas de Administração deveriam oferecer oportunidades para que os estudantes aumentassem sua compreensão sobre tal área, o que pode ser comprovado, analisando-se que as médias referentes às essas duas afirmações (as últimas duas da Tabela 1) foram as mais altas dentre os construtos desse fator.

Analisando-se o segundo fator, que retrata a 'necessidade da área de gestão ambiental no curso', observou-se que as médias foram relativamente mais baixas que as do fator anterior, sendo que três das cinco variáveis tiveram valores abaixo de 4 (ver Tabela 2). Já os desvios foram relativamente altos, comparativamente às variáveis do fator anterior, indicando que, no geral, as opiniões dos professores sobre esses pontos não são tão convergentes assim. A indicação foi de que os professores entendem os aspectos ambientais como da maior importância para o curso, 
porém não são igualmente certos de que a área seja realmente necessária no curso. Uma provável explicação para esta variação deve estar relacionada ao problema curricular e a grandes temas de interesse que podem ser abordados em cursos de Administração.

Tabela 1 - Relevância da área para o curso

\begin{tabular}{l|c|c}
\hline \multicolumn{1}{c|}{ Variável } & Média & Desvio \\
\hline O aprendizado sobre gestão ambiental é um assunto de grande importância para a & & \\
formação em Administração & 4,24 & 0,97 \\
Uma boa formação em Administração passa pela formação em gestão ambiental & 3,80 & 1,01 \\
$\begin{array}{l}\text { Graduandos em Administração devem saber como resolver problemas de gestão } \\
\text { ambiental }\end{array}$ & 4,02 & 0,85 \\
$\begin{array}{l}\text { Escolas de Administração deveriam oferecer oportunidades para que os estudantes } \\
\text { aumentem sua compreensão sobre gestão ambiental }\end{array}$ & 4,51 & 0,55 \\
$\begin{array}{l}\text { Escolas de Administração deveriam incentivar estudantes para se envolverem em } \\
\text { projetos ambientais }\end{array}$ & 4,37 & 0,70 \\
\hline
\end{tabular}

Fonte: Dados da pesquisa

Um dos pontos mais importantes com relação a esse segundo fator diz respeito ao fato de os professores acreditaram fortemente que os cursos de Administração não só deveriam envolver os estudantes em assuntos ambientais, como também deveriam ter nos seus currículos conteúdos e/ou disciplinas sobre gestão ambiental, o que reflete a importância cada vez maior que tal área vem conquistando dentro do meio acadêmico.

Tabela 2 - Necessidade da área no curso

\begin{tabular}{|c|c|c|}
\hline Variável & Média & Desvio \\
\hline Cursos de Administração deveriam envolver os estudantes em assuntos ambientais & 4,24 & 0,80 \\
\hline $\begin{array}{l}\text { Cursos de Administração deveriam preparar estudantes para serem líderes de projetos } \\
\text { ambientais }\end{array}$ & 3,37 & 1,02 \\
\hline $\begin{array}{l}\text { Cursos de Administração deveriam avaliar nos alunos conhecimentos sobre } \\
\text { responsabilidade ambiental }\end{array}$ & 3,83 & 0,80 \\
\hline $\begin{array}{l}\text { Cursos de Administração deveriam ter no currículo conteúdos/disciplinas sobre gestão } \\
\text { ambiental }\end{array}$ & 4,22 & 0,85 \\
\hline $\begin{array}{l}\text { Cursos de Administração deveriam ter tópicos nas várias disciplinas sobre } \\
\text { responsabilidade ambiental }\end{array}$ & 3,80 & 1,12 \\
\hline
\end{tabular}

Fonte: Dados da pesquisa

Já com relação às quatro variáveis sobre os 'interesses pessoais pela área ambiental', os resultados das médias, ao contrário das variáveis dos dois fatores acima descritos, foram notadamente mais baixos, conforme pode ser observado na tabela 3. Estes resultados são indicativos do pouco interesse dos professores em manterem envolvimentos futuros com a área de gestão ambiental, principalmente no que se refere à probabilidade de trabalhar nessa área ambiental. Ademais, os valores dos desvios, que foram bastante altos, indicam que esta posição é pouco convergente para a amostra em si. 
Tabela 3 - Interesse pessoal pela área ambiental

\begin{tabular}{l|c|c}
\hline \multicolumn{1}{c|}{ Variável } & Média & Desvio \\
\hline Probabilidade de inserir a gestão ambiental dentre os meus temas de ensino & 3,76 & 1,20 \\
Probabilidade de inserir a gestão a mbiental dentre os meus temas de pesquisa & 3,46 & 1,38 \\
Probabilidade de me envolver academicamente em projetos ambientais & 3,39 & 1,39 \\
Probabilidade de trabalhar (no mercado não-acadêmico) na área ambiental & 2,90 & 1,43 \\
\hline
\end{tabular}

Fonte: Dados da pesquisa

Para viabilizar uma análise agregada dos três aspectos avaliados, decidiu-se pela composição de cada bloco a partir das médias dos construtos (este procedimento foi viabilizado pelo sentido das variáveis, e pelos resultados do coeficiente Alpha de Cronbach, que foi maior que 0,6 em cada dimensão). Na tabela 4, constam a média e o desvio padrão de cada uma das variáveis.

Em uma análise dos três fatores integrados, percebe-se que: na medida integrada relativa à 'relevância da área de gestão ambiental para o curso', a média teve um valor acima de 4 $(4,20)$, o que pode ser considerado elevado, já que as escalas foram de 1 a 5 . Já no segundo fator, a 'necessidade da área de gestão ambiental para o curso', ficou com uma média $(3,89)$, em torno de 4, o que, apesar de ser um pouco abaixo do primeiro, ainda indica um nível elevado de concordância com as afirmações integradas dentro deste item. Por fim, o terceiro fator, que congrega as 'intenções de envolvimento pela área ambiental', teve uma média considerada baixa $(3,38)$, principalmente quando comparada aos resultados dos outros dois fatores anteriormente comentados.

Todavia, com relação aos valores dos desvios padrão, tem-se que, nos dois primeiros fatores, os valores obtidos foram considerados baixos (0,59 e 0,58, respectivamente), indicando que tais posições são relativamente convergentes para a amostra. Já no caso do terceiro e último fator, o desvio $(1,16)$ foi considerado relativamente alto, o que demonstra uma posição bem distinta em relação aos outros dois fatores e suas medidas integradas.

Percebe-se, assim, que os professores entendem como sendo altamente relevante a presença da área de gestão ambiental nos cursos de Administração e também consideram elevada a necessidade da área no curso e a existência dos estudos de gestão ambiental dentro dos cursos de Administração. Porém, este entusiasmo que os professores dispõem quanto à relevância da gestão ambiental não segue a mesma linha no que diz respeito às intenções dos mesmos em ampliarem seu envolvimento em tal área.

Tabela 4 - Medidas integradas

\begin{tabular}{l|c|c}
\hline \multicolumn{1}{c|}{ Variável } & Média & Desvio \\
\hline Relevância da área para o curso & 4,20 & 0,59 \\
Necessidade da área no curso & 3,89 & 0,58 \\
Intenções de envolvimento pela área & & \\
ambiental & 3,38 & 1,16 \\
\hline
\end{tabular}

Fonte: Dados da pesquisa 
Complementarmente aos resultados e relações apresentadas nas tabelas anteriores, têmse também alguns detalhes adicionais importantes que merecem ser comentados, conforme se fará no item subsequente.

\subsection{Comentários adicionais}

Entende-se que os resultados do estudo trazem algumas informações que os autores consideram relevantes, principalmente com relação aos estudos da área de gestão ambiental nos cursos de Administração. Sabe-se, contudo, que o campo da gestão ambiental pode ser considerado ainda em formação, a despeito de já ter seu elenco de atividades de formação e de pesquisa. Adicionalmente, o papel dos cursos de Administração, neste campo, parece ainda incerto. A perspectiva da multidisciplinaridade prevalecente nas avaliações das questões ambientais parece estar atendendo adequadamente às demandas atuais.

Todavia, é difícil pensar em uma perspectiva de gestão ambiental consistente e profissional, sem uma participação mais ativa e de liderança da área de Administração. Considerando que tal perspectiva necessita também de uma participação ativa não só dos estudantes, mas também dos professores, os resultados desta pesquisa reafirmam o desafio, na medida em que esses mesmos professores apontaram uma real preocupação com a área, conforme atestaram as médias e os desvios padrão das variáveis dos construtos relacionados à relevância da gestão ambiental para os cursos de Administração, muito embora o interesse pessoal em se engajar em atividades associadas à gestão ambiental no futuro tenha sido considerado ainda baixo.

As razões para tal desinteresse, todavia, não puderam ser suficientemente exploradas neste trabalho. É provável que a baixa intenção de se envolver de forma não-acadêmica com a área, explique-se pelo fato de os professores não a perceberem como um campo de atuação que ofereça condições reais e seguras de empregabilidade, muito embora, em termos acadêmicos, uma grande parte destes mesmos professores tenha demonstrado interesse em inserir a temática nos seus projetos de ensino dentro de sala de aula. Seja como for, outros estudos são indicados para explorar mais profundamente tais suposições.

Caberia, assim, que instituições, gestores, professores e pesquisadores direcionassem esforços no sentido de despertar uma melhor atitude dos professores com relação à exploração da temática ambiental nos cursos de Administração, sendo mais evidente a necessidade de uma maior preocupação em desenvolverem ações e projetos que envolvam não apenas o interesse de forma efetiva, mas também a demonstração da importância em se ter disciplinas da área nos currículos desses cursos em questão.

\section{Considerações finais}

Este estudo partiu do pressuposto da existência, no universo acadêmico brasileiro, da necessidade de se priorizar a formação dos profissionais especializados na área ambiental. Dessa forma, os cursos de Administração são contextos adequados para este propósito, pois são os espaços a partir dos quais sairão a maioria dos futuros líderes que terão oportunidade de executarem ações práticas dentro de uma adequada convivência entre o meio ambiente e as organizações.

Nesses termos, este trabalho atendeu ao seu objetivo, no qual se pôde verificar consistentemente tal questão pela perspectiva dos professores. Acredita-se que os resultados do estudo constituem informações relevantes para os gestores de cursos de Administração e de Institui- 
ções de Ensino Superior, pois trazem subsídios que viabilizam um melhor direcionamento no processo de formação.

Acredita-se também que a abordagem desenvolvida seja do interesse de gestores de instituições de ensino e de autores de materiais didáticos da área de gestão, os quais têm, agora, informações para embasar uma formatação mais consistente dos conteúdos, a partir da agregação de tópicos sobre gestão ambiental nas disciplinas e em materiais como livros e apostilas. Adicionalmente, os resultados juntam-se às conclusões de outros estudos, acreditando-se que, tudo isso, trará contribuições para novas pesquisas sobre o tema.

Por outro lado, os resultados foram limitados, uma vez que a amostra foi restrita a instituições cearenses, além do fato de a amostragem ter sido feita por conveniência. Seria relevante uma replicação deste estudo em outros estados e regiões brasileiras, de preferência com métodos de amostragem mais rigorosos. O estudo também foi restrito a três construtos principais, além de ter deixado de abordar outras possibilidades. Recomenda-se, portanto, que outros tópicos associados ao tema gestão ambientais sejam avaliados, como aqueles referentes, por exemplo, à ética, à responsabilidade sócio-ambiental, dentre outros.

Outros trabalhos poderão investigar o posicionamento de estudantes e de empresários sobre como deve ser o processo de formação do futuro administrador ambiental e, a partir daí, comparar com os resultados aqui alcançados na busca de uma convergência entre formação e aplicação prática dos conhecimentos acadêmicos.

\section{Referências bibliográficas}

ABNT. Associação Brasileira de Normas Técnicas. NBR ISO 14001: sistema da gestão ambiental - requisitos com orientação para uso. Rio de Janeiro, ABNT, 2004.

ANDRADE, R.O.B. et al. Pesquisa nacional sobre o perfil, formação, atuação e oportunidades de trabaIho do administrador. Brasília: Conselho Federal de Administração - CFA, 2006.

BAGOZZI, R.P.; EDWARDS, J.R. A general approach for representing constructs in organizational research. Organizational Research Methods. v. 1, n. 1, p. 4587, 1998.

BARBIERI, J.C. Gestão ambiental empresarial: conceitos, modelos e instrumentos. São Paulo: Saraiva, 2004.

BRASIL. Lei no 9.795, de 27 de abril de 1999. Dispõe sobre a educação ambiental, institui a Política Nacional de Educação Ambiental e dá outras providências. Diário Oficial da União, Brasília, DF, 28 de abril de 1999. Disponível em: <http:// www. planalto.gov.br/CCIVIL/LEIS/L9795.htm>. Acesso em: 05 mar. 2008.

CAPRA, F. (Org.). Alfabetização ecológica: a educação das crianças para um mundo sustentável. São Paulo: Cultrix, 2007.

DIAS, R. Gestão ambiental: responsabilidade social e sustentabilidade. São Paulo: Atlas, 2006.

EGRI, C. P.; PINFIELD, L. Organizations and the biosphere: ecologies and environments. In: CLEGG, S.; HARDY, C.; NORD, W. R. (Ed.). Handbook of organization studies. London: Sage, 1996. p. 459483.

ESALQ. Escola Superior de Agricultura Luiz de Queiroz. Projeto pedagógico do curso de Gestão Ambiental. Disponível em: <http:// www.esalq.usp.br/> Acesso em: 05 mar. 2008.

ESTY, D. C.; WINSTON, A. S. Green to gold: how smart companies use environmental strategy to innovate, create value, and build competitive advantage. New Haven, CT and London: Yale University Press, 2006.

FUKUKAWA, K.; SHAFER, W. E.; LEE, G. M. Values and attitudes toward social and environmental accountability: a study of MBA students. Journal of Business Ethics, n. 71, p. 381-394, Springer 2007. 
GONÇALVES-DIAS, S. L. F. et al. A inserção da temática ambiental em cursos de Administração: uma tipologia para (re) pensar a formação de administradores. Encontro Anual da Associação Nacional dos Cursos de Pós-Graduação em Administração. 30. Anais eletrônicos... Salvador: ANPAD, 2006.

HAIR, J.F. et al. Análise multivariada de dados. 5. ed. Porto Alegre: Bookman, 2005.

INSTITUTO ETHOS. Aprendendo a lição de Chaco Canyon: do desenvolvimento sustentável a uma vida saudável. São Paulo: Instituto Ethos, 2005a.

- O compromisso das empresas com o meio ambiente. São Paulo: Instituto Ethos, 2005b.

LASH, J.; WELLINGTON, F. Competitive advantage on a warming planet. Harvad Business Review, March 2007.

MALHOTRA, N. K. Marketing research: an applied orientation. 3. ed. New Jersey: Prentice-Hall, 1999.

MAXIMIANO, A. C. A. Introdução à Administração. 6. ed. São Paulo: Atlas, 2004.

MELO NETO, F. P.; BRENNAD, J. M. Empresas socialmente sustentáveis: o novo desafio da gestão moderna. Rio de Janeiro: Qualitymark, 2004.

REIGOTA, M. O que é educação ambiental. São Paulo: Brasiliense, 1994.

RIGONAT, M. C. Hacia una educación ambiental anclada en el local. Revista Gestão em Ação, Salvador, v. 5, n. 2, p. 127-144, jul./dez. 2002.

NASCIMENTO, L. F.; LEMOS, A. D. C.; MELLO, M. C. A. Gestão sócio-ambiental estratégica. Porto Alegre: Bookman, 2008.

SANTOS, T. A. et al. O valor das pequenas coisas: a difícil aprendizagem na prática da gestão ambiental por acadêmicos do curso de Administração. In: ENCONTRO ANUAL DA ASSOCIAÇÃO NACIONAL DOS CURSOS DE PÓS-GRADUAÇÃO EM ADMINISTRAÇÃO, 24., 2000, Florianópolis. Anais eletrônicos... Florianópolis: ANPAD, 2000.

SEIFFERT, M. E. B. Gestão ambiental: instrumentos, esferas de ação e educação ambiental. São Paulo: Atlas, 2007.
SHAFER, W. E. Social paradigms and attitudes toward environmental accountability. Journal of Business Ethics, n. 65, p. 121-147, Springer 2006.

SILVA, L. M. T. da; SILVA, M. P. da; ENDERS, W. T. Gestão ambiental e desempenho organizacional: um estudo de suas relações no setor hoteleiro. In: ENCONTRO ANUAL DA ASSOCIAÇÃO NACIONAL DOS CURSOS DE PÓS-GRADUAÇÃO EM ADMINISTRAÇÃO, 30., 2006, Salvador. Anais eletrônicos... Salvador: ANPAD, 2006.

SLEEPER, B. J. et al. Scale and study of student attitudes toward business education's role in addressing social issues. Journal of Business Ethics, n. 68, p. 381-391, Springer 2006.

TACHIZAWA, T. Gestão ambiental e responsabilidade social corporativa: estratégias de negócios focadas na realidade brasileira. 4. ed. São Paulo: Atlas, 2007. 